\title{
Activation and inhibition of stimulus features in conjunction search
}

\author{
HIDEYA KOSHINO \\ California State University, San Bernardino, California
}

\begin{abstract}
Two visual search experiments were conducted to examine how activation of target-relevant features and inhibition of target-irrelevantfeatures are involved in conjunction search. The hypothesis was that if an excitatory mechanism is involved, it should be revealed as facilitation when a target and distractors are repeated in two successive displays. If an inhibitory mechanism is involved, suppression should be obtained when distractor features from one display determine the target in the following display. The results of Experiment 1 showed that facilitation was observed consistently across two set sizes (5 and 9), whereas suppression was obtained only with larger set size (9). This pattern of results was replicated and extended in Experiment 2 with different set size. It seems that both excitatory and inhibitory mechanisms are involved in conjunction search. The excitatory mechanism seems to play a role in conjunction search regardless of search difficulty, whereas the inhibitory mechanism might play a role only when set size is larger.
\end{abstract}

This paper is concerned with underlying mechanisms in conjunction search. In conjunction search, a target is defined by a combination of two or more features. The original feature integration theory of attention (FIT) developed by Treisman and her colleagues (e.g., Treisman, 1988; Treisman \& Gelade, 1980; Treisman \& Gormican, 1988) showed that response times to make target present/absent decisions depend on set size. It is usually found that the slope ratio between target present and absent trials is approximately 1:2. On the basis of these results, the original FIT claimed that serial scanning is necessary in order to integrate different features (e.g., color and form) into a coherent object image in conjunction search. However, it was later found that, in some cases, conjunction search may be much more efficient than would be predicted by the serial self-terminating model (see, e.g., Duncan \& Humphreys, 1989, 1992; Egeth, Virzi, \& Garbart, 1984; McLeod, Driver, \& Crisp, 1988; Nakayama \& Silverman, 1986; Wolfe, Cave, \& Franzel, 1989). These findings led to the modification of the original FIT.

One of the major points in the modification of the original FIT is the idea that the results of the initial, preattentive stage guide the allocation of attention in the second, attentive stage. Regarding this attentional guidance, two types of hypotheses have been proposed. One hypothesis emphasizes excitatory mechanisms and claims that con-

This research was supported by a professional development grant from California State University, San Bernardino. I thank Jim Juola, George Kellas, and Bob Ricco for their valuable comments and suggestions throughout this study. I am also very grateful to Harold Pashler, Todd Horowitz, Phillip Merikle, and an anonymous reviewer for very helpful comments on the earlier versions of the manuscript. Please address correspondence to H. Koshino, Department of Psychology, California State University, 5500 University Parkway, San Bernardino, CA 92407 (e-mail: hkoshino@csusb.edu). junction search is based on activation of task-relevant features (e.g., Friedman-Hill \& Wolfe, 1995; Wolfe, 1994; Wolfe et al., 1989). In this case, both of the target-relevant features are activated, and, therefore, the area that contains the target is doubly activated. For example, when the target is a red X and distractors are red Os and green Xs, all locations that contain red are activated and all locations that contain Xs are also activated. Therefore, a target location that contains both red and $\mathrm{X}$ is doubly activated. Friedman-Hill and Wolfe provided evidence for feature activation in subset search tasks. They found that heterogeneity of items that shared features with the target increased the search slope, whereas heterogeneity of items whose features were unrelated to the target did not affect the search slope. They concluded that subset search is based on activation of target-relevant features rather than on inhibition of target-irrelevant features.

The other hypothesis claims that conjunction search is based on inhibition of task-irrelevant features (see, e.g., Treisman, 1993; Treisman \& Sato, 1990). According to Treisman and Sato (also Treisman, 1993), the master map of locations receives inhibition from feature maps containing task-irrelevant features, thus reducing the interference from distractors. Treisman and Sato conducted several experiments to examine the feature inhibition hypothesis. In one experiment, the main task was typical conjunction search in which a target was defined by color and orientation. The critical manipulation was the relative similarity of distractor items to the target. Treisman and Sato hypothesized that if conjunction search is based on activation of task relevant features, the additional dissimilar items should not affect search efficiency. However, if the search process is based on feature inhibition, the addition of dissimilar distractors should have some influence on the search efficiency, because participants would have to inhibit those dissimilar items as well. The 
results showed that the addition of dissimilar items had a significant effect on search efficiency; search was slower with the additional items than without them. Treisman and Sato concluded that their results provided evidence for the feature inhibition hypothesis.

In some studies, different paradigms have been used to examine activation and inhibition in visual search. For example, Cave and his colleagues (e.g., Cepeda, Cave, Bichot, \& Kim, 1998; Kim \& Cave, 1995) investigated excitatory and inhibitory mechanisms in visual search by using a dot probe task, in which a dot probe was presented at different locations in the visual field after the search display. When the dot probes were presented at previous target locations, responses were facilitated, whereas when they were presented at previous distractor locations, responses were inhibited.

Other researchers have used measures similar to a negative priming paradigm (e.g., Milliken, Joordens, Merikle, \& Seifert, 1998; Neill, 1977; Tipper, 1985). For example, Maljkovic and Nakayama (1994, 1996) investigated priming effects in pop-out displays. RTs decreased as the number of trial increased when a target color was kept the same while a distractor color was changed, as well as when a distractor color was kept the same while a target color was changed. They found facilitation and inhibition based on the attention-driven feature (color) and the spatial location.

Horowitz and Wolfe (1996) examined the involvement of a location-based inhibitory mechanism in conjunction search. Their task was a color $\times$ orientation conjunction search. There were three distractor conditions: (1) color distractors, in which the color of the distractor was the same as that of the target but the orientation was not; (2) orientation distractors, in which the orientation of the distractor was the same as that of the target but the color was not; and (3) antitargets, in which the distractor did not share any features with the target. RTs were shorter for the target appearing at the location occupied by the previous target. However, RTs were longer for the target appearing at the location occupied by the antitarget in the previous trial. RTs were about the same for targets appearing at the location occupied by color and orientation distractors. Horowitz and Wolfe concluded that attentional guidance in conjunction search appears to involve both activation of target locations and inhibition of nontarget locations.

In the present study, distractor features (color and form) were manipulated rather than spatial locations in order to examine how excitatory and inhibitory mechanisms are involved in conjunction search. A prime-probe design was used, so that stimulus activation and inhibition in prime displays were measured as carryover effects in the following probe displays. The relationships of stimulus features were manipulated between the prime and probe displays. If an excitatory mechanism was involved, target-relevant stimulus features should be activated in the prime trial and therefore RTs to find the target in the probe trial should be shorter (facilitation) when the target features were repeated in the probe trials. Al- ternatively, if target-irrelevant features were inhibited, then RTs should be longer (suppression) for conditions in which distractor features from a preceding trial became target features than for a control condition in which there was no relationship between prime and probe stimuli. Because a conjunction target is defined by the combination of color and form, an effect of each stimulus dimension could be manipulated independently. In this case, there were three possible conditions: (1) the color of the prime distractor became the color of the probe target, (2) the form of the prime distractor became the form of the probe target, and (3) both the color and form of the prime distractors were combined to determine the probe target.

\section{EXPERIMENT 1}

\section{Method}

Participants. Fifteen students from California State University, San Bernardino, participated for course credit. All had normal or corrected-to-normal vision and no reported color deficiency.

Stimuli. Stimulus presentation and data collection were controlled by a 486 IBM-compatible computer with a 15 -in. SVGA monitor. The task was visual search for a conjunction target that was defined by a combination of color (light red, light magenta, light green, and blue) and form (N, V, X, and Z). In each trial, two colors and two forms were used to define a target and distractors. The stimuli were arranged in a circular fashion, with 12 possible target locations. From the viewing distance of about $80 \mathrm{~cm}$, the display diameter subtended approximately $3.9^{\circ}$ of visual angle $(5.5 \mathrm{~cm})$. The height and width of each letter were $0.7 \mathrm{~cm}\left(0.5^{\circ}\right)$ and $0.6 \mathrm{~cm}\left(0.4^{\circ}\right)$, respectively.

Design. A prime-probe design was used to measure intertrial dependency, and there were five levels for the priming factor: (1) The color and form of the prime target were identical to those of the probe target (identical: ID), (2) the color of the distractors on prime trials became the target color on the probe trials (color related: CR); (3) the form of the distractors on the prime trials became the target form (form related: FR); (4) both the color and form of the prime distractors became the target color and form on the probe trials (both related: BR); and (5) all items were unrelated between the prime and probe displays (unrelated: UR). The relationships between prime

Table 1

Relationships Between Prime and Probe Stimuli and Examples in Experiment 1

\begin{tabular}{|c|c|c|c|c|c|c|c|}
\hline \multirow{2}{*}{\multicolumn{2}{|c|}{ Stimulus }} & \multicolumn{2}{|c|}{ Target } & \multicolumn{2}{|c|}{ Distractor 1} & \multicolumn{2}{|c|}{ Distractor 2} \\
\hline & & Color & Form & Color & Form & Color & Form \\
\hline \multicolumn{2}{|l|}{ Prime } & Red & $X$ & Red & $\mathrm{N}$ & Green & $\mathrm{X}$ \\
\hline \multirow[t]{10}{*}{ Probe } & ID & $\mathrm{C}(\mathrm{t})$ & $\mathrm{F}(\mathrm{t})$ & $C(t)$ & $\mathrm{F}(\mathrm{d})$ & $\mathrm{C}(\mathrm{d})$ & $\mathrm{F}(\mathrm{t})$ \\
\hline & Example & Red & $X$ & Red & $\mathrm{N}$ & Green & $\mathrm{X}$ \\
\hline & $\mathrm{CR}$ & $\mathrm{C}(\mathrm{d})$ & $\mathrm{F}(\mathrm{u})$ & $\mathrm{C}(\mathrm{d})$ & $\mathrm{F}(\mathrm{u})$ & $\mathrm{C}(\mathrm{u})$ & $\mathrm{F}(\mathrm{u})$ \\
\hline & Example & Green & Z & Green & $V$ & Blue & Z \\
\hline & FR & $\mathrm{C}(\mathrm{u})$ & $\mathrm{F}(\mathrm{d})$ & $\mathrm{C}(\mathrm{u})$ & $\mathrm{F}(\mathrm{u})$ & $\mathrm{C}(\mathrm{u})$ & $\mathrm{F}(\mathrm{d})$ \\
\hline & Example & Blue & $\mathrm{N}$ & Blue & V & Magenta & $\mathrm{N}$ \\
\hline & $\mathrm{BR}$ & $\mathrm{C}(\mathrm{d})$ & $\mathrm{F}(\mathrm{d})$ & $\mathrm{C}(\mathrm{d})$ & $\mathrm{F}(\mathrm{u})$ & $\mathrm{C}(\mathrm{u})$ & $\mathrm{F}(\mathrm{d})$ \\
\hline & Example & Green & $\mathrm{N}$ & Green & V & Magenta & $\mathrm{N}$ \\
\hline & UR & $\mathrm{C}(\mathrm{u})$ & $\mathrm{F}(\mathrm{u})$ & $\mathrm{C}(\mathrm{u})$ & $\mathrm{F}(\mathrm{u})$ & $\mathrm{C}(\mathrm{u})$ & $\mathrm{F}(\mathrm{l}$ \\
\hline & Example & Magenta & Z & Magenta & $\mathrm{V}$ & Blue & \\
\hline
\end{tabular}

Note-C, Color; F, Form; t, prime target; d, prime distractor; u, unused in the prime. Therefore, $\mathrm{C}(\mathrm{t})$, color of prime target; $\mathrm{F}(\mathrm{t})$, form of prime target; $\mathrm{C}(\mathrm{d})$, color of prime distractor; $\mathrm{F}(\mathrm{d})$, form of prime distractor. For example, a probe target for the ID condition is defined by a combination of the color of the prime target and the form of the prime target. 
and probe stimuli and their examples are shown in Table 1. Stimulus locations were randomized in each display, and therefore there was no relationship between prime and probe displays in this regard. There were two levels of set size (5 and 9). The set size remained the same between a prime and the following probe, though set size was randomized within a block of trials.

For the priming conditions, both prime and probe displays contained a target. There were three other types of prime-probe pairs: target present-absent, target absent-present, and target absentabsent. These three conditions were included in order to measure the slopes of the functions relating RT to set size in target-present and target-absent trials.

Procedure. At the beginning of each trial, a conjunctively defined target (e.g., red X) was presented at the center of the computer display for $500 \mathrm{msec}$ and then a stimulus display appeared with no interstimulus interval (ISI). Participants were asked to press a right hand key (/) when the target was present and a left key $(\mathrm{z})$ when the target was absent. The stimulus display remained on until the participant made a response or $3 \mathrm{sec}$ elapsed. When the participant committed an error, the computer emitted a beep, and the same trial was repeated as a buffer trial. The response-stimulus interval (RSI) between a prime and a probe trial was $500 \mathrm{msec}$. The RSI between a probe and the next prime trial was $1,500 \mathrm{msec}$. Each participant was given a practice session consisting of 128 trial pairs (prime and probe) followed by the main session consisting of 420 trial pairs. The entire session took approximately $1 \mathrm{~h}$.

\section{Results}

The mean overall error rate was $3.3 \%$. Trials in which an error was made either to the prime or to the probe display were excluded from the analysis. Mean RTs and error rates are shown in Table 2. The mean RTs and error rates were positively correlated across conditions $[r(14)=$ $0.71, p<.01]$, suggesting no speed-accuracy tradeoff. The RT data were submitted to a 2 (set size) $\times 5$ (priming) repeated measures analysis of variance (ANOVA). RTs were significantly longer for set size 9 than set size 5 $[F(1,14)=183.7, p<.001]$. There were significant differences among priming conditions $[F(4,56)=10.22$, $p<.001]$. The priming factor interacted with set size $[F(4,56)=3.16, p<.05]$. The patterns of the priming effects were different between two set size conditions.

Planned contrasts were performed to examine whether RTs for the priming conditions were different from those for the UR condition. For set size 5, the ID condition produced a significantly shorter RT than did the UR condition $[t(56)=3.63, p<.01]$. The difference between the $\mathrm{CR}$ and UR conditions was marginally significant $[t(56)=$

Table 2

Mean Response Times (RT, in Milliseconds) and Error Rates (\%) for Priming Conditions in Experiment 1

\begin{tabular}{|c|c|c|c|c|c|c|c|}
\hline \multirow{2}{*}{$\begin{array}{l}\text { Set } \\
\text { Size }\end{array}$} & & & \multicolumn{5}{|c|}{ Priming Conditions } \\
\hline & & & ID & $\mathrm{CR}$ & FR & BR & UR \\
\hline \multirow[t]{4}{*}{5} & RT & $M$ & 605 & 638 & 658 & 663 & 672 \\
\hline & & $S D$ & 92.8 & 116.6 & 100.3 & 121.4 & 137.5 \\
\hline & Error & $M$ & 0.8 & 3.1 & 2.8 & 1.1 & 2.5 \\
\hline & & $S D$ & 1.7 & 4.3 & 4.4 & 2.5 & 3.5 \\
\hline \multirow[t]{4}{*}{9} & RT & $M$ & 714 & 815 & 791 & 802 & 763 \\
\hline & & $S D$ & 101.3 & 156.8 & 186.5 & 149.6 & 113.6 \\
\hline & Error & $M$ & 1.7 & 5.3 & 3.6 & 4.2 & 4.7 \\
\hline & & $S D$ & 3.1 & 7.1 & 4.7 & 4.5 & 4.1 \\
\hline
\end{tabular}

$1.84, .05<p<.10]$. No other contrasts were significant for set size 5. For set size 9, the RT for the ID condition was significantly shorter than that for the UR condition $[t(56)=2.65, p<.05]$. However, the RTs for the CR and $\mathrm{BR}$ conditions were significantly longer than the RTs for the UR condition $[t(56)=2.82, p<.01$ and $t(56)=2.11$, $p<.05$, respectively].

The error data were also subjected to a 2 (set size) $\times$ 5 (priming conditions) repeated measures ANOVA. The participants made more errors for set size 9 than for set size $5[F(1,14)=12.04, p<.01]$. The priming effect was also significant $[F(4,56)=3.82, p<.01]$. Participants made fewer errors in the ID condition than in the other conditions. However, the priming effect did not interact with set size $[F(4,56)<1]$.

Because the present task involved conjunction search, slopes and intercepts for target present $(\mathrm{Y}=26.6 \mathrm{X}+$ $565)$ and absent $(Y=55.4 X+614)$ trials were also computed on the basis of target present and absent conditions from the probe trials. The slope ratio was 2.1:1 between absent and present trials, suggesting that the participants in this experiment performed conjunction search in a typical way (i.e., in agreement with a serial self-terminating search model).

\section{Discussion}

There are two major results from Experiment 1. One is that significant facilitatory priming was obtained in the ID condition for both set sizes 5 and 9 . When items were identical in prime and probe displays, RTs to find targets in the probe display were facilitated regardless of set size. These results suggest that target-relevant features are activated in conjunction search, although it is possible that the results might also reflect some other factors such as the fact that participants did not have to change target template since all items remained the same between a prime and a probe trial in the ID condition.

The second finding concerns the interaction between the priming factor and set size for RT data. In the CR condition, a marginally significant facilitation was obtained for set size 5, whereas significant suppression was observed for set size 9. Suppression was significant for set size 9 but not for set size 5 in the BR condition. In other words, in the $\mathrm{CR}$ and BR conditions, suppression was significant for the larger set size (9) but not for the smaller set size (5). Is there any relationship between the magnitude of suppression and stimulus conditions? Some researchers using negative priming paradigms have found facilitation rather than suppression in certain conditions, such as when using short exposures of the targets (e.g., Allport, Tipper, \& Chmiel, 1985) or when the feature was not associated with the current behavioral goal (e.g., Tipper, Weaver, \& Houghton, 1994), and therefore it has been suggested that all information is first activated and then target-irrelevant information is inhibited. In the present experiment, it was possible that all features, target relevant and irrelevant, were activated initially and that activation of target-relevant features might have been sufficient to find a target when the 
set size was 5. However, target-irrelevant features might need to be inhibited when the set size was 9. In other words, the magnitude of suppression may have depended on search difficulty. The more difficult the search, the greater the suppression. In the present experiment, search was easier for set size 5 (mean RT $=698 \mathrm{msec}$ for target-present trials) than for set size 9 (mean RT $=908 \mathrm{msec}$ for targetpresent trials). When visual search was easy, the excitatory mechanism alone might be sufficient to find the target and the inhibitory mechanism might not need to be involved. On the other hand, inhibition of target-irrelevant features might be required when search was more difficult. In order to investigate this possibility, Experiment 2 was designed with three levels of set size (3, 7, and 11). If the hypothesis above was true, suppression should be observed only at greater set sizes, whereas facilitation should be obtained across all the set sizes.

\section{EXPERIMENT 2}

\section{Method}

Participants. Fifteen students from California State University, San Bernardino, participated for course credit. All had normal or corrected-to-normal vision and no reported color deficiency. None had participated in Experiment 1.

Stimuli. The same stimuli as in Experiment 1 were used. Stimulus presentation and data collection were done in the same way as Experiment 1.

Design. The same prime-probe design was used, and there were three levels of the priming factor: (1) Both the color and form of the targets were identical between prime and probe trials (identical: ID); (2) both the color and form of the prime distractors became the target color and form in the probe trials (both related: BR); and (3) all items were unrelated (unrelated: UR). There were three levels in the set size factor (3, 7, and 11).

Procedure. The procedure was basically the same as in Experiment 1, except that set size was blocked in Experiment 2. The presentation order of blocks was randomized. There were 96 trial pairs in each set size condition, resulting in 288 trial pairs in total. Each participant received a practice session before the main session, and the entire experiment took approximately $1 \mathrm{~h}$ to complete.

Table 3

Mean Response Times (RT, in Milliseconds) and Error Rates (\%) for Priming Conditions in Experiment 2

\begin{tabular}{cccccc}
\hline \multirow{2}{*}{$\begin{array}{c}\text { Set } \\
\text { Size }\end{array}$} & & & \multicolumn{3}{c}{ Priming Conditions } \\
\cline { 3 - 5 } 3 & & & ID & BR & UR \\
\hline \multirow{2}{*}{ RT } & $M$ & 527 & 554 & 574 \\
& & $S D$ & 62.7 & 85.1 & 93.0 \\
& \multirow{2}{*}{ Error } & $M$ & 0.8 & 4.2 & 3.8 \\
& & $S D$ & 2.2 & 7.3 & 4.0 \\
7 & \multirow{2}{*}{ RT } & $M$ & 671 & 759 & 721 \\
& \multirow{2}{*}{ Error } & $M D$ & 115.1 & 150.9 & 118.2 \\
& & $S D$ & 3.3 & 2.5 & 1.3 \\
& \multirow{2}{*}{ RT } & $M$ & 792 & 4.6 & 3.5 \\
& \multirow{2}{*}{ Error } & $M$ & 120.9 & 109.2 & 112.3 \\
& & $S D$ & 1.3 & 5.0 & 6.7 \\
& & $S D$ & 2.6 & 4.8 & 6.9 \\
\hline
\end{tabular}

\section{Results}

The overall error rate was $3.0 \%$. Trials in which an error was made either to the prime or to the probe display were excluded from the analysis. Mean RTs and error rates are shown in Table 3. The mean RTs and error rates were not correlated $[r(16)=0.36$, n.s.], suggesting no speed-accuracy tradeoff. The RT data were submitted to a 3 (set size) $\times 3$ (priming) repeated measures ANOVA. RTs increased as set size increased $[F(2,28)=90.7, p<$ $.001]$. There were differences among priming conditions $[F(2,28)=13.9, p<.001]$. A significant interaction was found between the priming and set size conditions $[F(4,56)=2.62, p<.05]$, indicating that the magnitudes of priming depended on set size.

Planned contrasts revealed the following. First, significant facilitation was obtained for the ID condition in all three set sizes $[t(56)=2.30, p<.05$, for set size $3 ; t(56)=$ $2.49, p<.05$, for set size 7 ; and $t(56)=2.88, p<.01$, for set size 11]. For the BR condition, as was predicted, the magnitude of suppression increased as set size increased. Suppression was not significant for set size $3[t(56)=$ 0.98 , n.s.], marginally significant for set size $7[t(56)=$ $1.81, .05<p<.10]$, and significant for set size 11 $[t(56)=2.49, p<.05]$. In order to confirm this increase in suppression across set size, the RT difference between the BR and UR conditions was computed for each set size, and then subjected to a trend analysis. A significant linear trend was obtained $[F(1,14)=12.42, p<.01]$, indicating that the magnitude of suppression for the BR conditions increased as set size increased.

The error data were also submitted to a 3 (set size) $\times$ 3 (priming conditions) repeated measures ANOVA. Neither the set size nor the priming main effect was significant $[F(2,28)=2.44, p>.10$, and $F(2,28)=2.16, p>.10$, respectively]. However, an interaction was significant $[F(4,56)=2.73, p<.05]$. In the BR and UR conditions, the error rates were higher for set size 11 . The effect did not hold for the ID condition.

An RT $\times$ set size function was also computed separately for each priming condition. It was $Y=33.2 X+431$ for the ID condition, $Y=43.5 X+433$ for the $B R$ condition, and $\mathrm{Y}=34.6 \mathrm{X}+473$ for the UR condition. A one-way ANOVA for slopes revealed significant differences among them $[F(2,28)=6.01, p<.01]$. Planned contrasts for slopes showed that the slope for the BR condition was significantly steeper than that for the UR condition $[t(28)=2.76, p<.05]$, though there was no difference between slopes for the ID condition and UR condition $[t(28)<1]$. Another one-way ANOVA revealed that the differences among intercepts were marginally significant $[F(2,28)=3.16, p<.10]$. Another set of contrasts for the intercepts showed that the intercept for the ID condition was significantly smaller than that for the UR condition $[t(28)=2.24, p<.05]$, and that the intercept for the $\mathrm{BR}$ condition was smaller than that for the UR condition $[t(28)=2.11, p<.05]$. 


\section{Discussion}

There were two main results in Experiment 2. One was that significant facilitation was obtained for all three levels of set sizes. The other was that suppression was observed only for set size 11 . The planned contrast and the trend analysis indicated that the magnitude of suppression increased as set size increased. The results replicated and extended the findings of Experiment 1, and they provide support for the hypothesis that target-irrelevant features are inhibited only when search is difficult.

The analyses of the RT $\times$ set size functions seem to support the same conclusion. The RT $\times$ set size functions for the ID and UR conditions have the same slope, and the intercept was greater for the UR than for the ID condition. This difference in the intercept might have resulted from the advantage in the ID condition caused by the repetition of the same stimuli between the prime and probe trials. The repetition of the same stimuli reduced the overall time to examine the display, though the time that was required to check each item remained the same.

The slope for the BR condition is steeper than that for the ID and UR conditions. This means that it took longer for participants to check items in the display for the $\mathrm{BR}$ condition. In the probe display of the BR condition, each item had at least one feature from the distractors in the prime display. For example, if the prime target was a red $\mathrm{X}$ and prime distractors were red Ns and green Xs, as shown in Table 1, then green and $\mathrm{N}$ were inhibited during the prime trial. In the probe trial, the target was a green $\mathrm{N}$ by the requirement of the condition (the distractor features of the prime display defined the probe target), and distractors might be green Vs and magenta Ns as shown in Table 1. In this probe display, each item had at least one feature that was inhibited in the prime display. One interpretation of the results is that attentional guidance might be impaired when the features that were inhibited in the prime display became the target features in the probe display.

\section{GENERAL DISCUSSION}

The results can be summarized as follows. First, facilitation was found for all set sizes ( 5 and 9 in Experiment 1; 3, 7, and 11 in Experiment 2). This suggests that activation of target-relevant features is involved in conjunction search regardless of set size, although the present results cannot be conclusive with regard to feature-based activation because of the limitation of the ID condition discussed in Experiment 1.

Second, suppression was observed only for larger set size conditions (in the $\mathrm{CR}$ and $\mathrm{BR}$ conditions for set size 9 in Experiment 1 and in the BR condition for set size 11 in Experiment 2), suggesting that inhibition of targetirrelevant features plays a role when set size is large, and, thus, that search is more difficult.

When the present results are combined with other findings (e.g., Friedman-Hill \& Wolfe, 1995; Horowitz \& Wolfe, 1996; Treisman, 1993; Treisman \& Sato, 1990;
Wolfe, 1994), it seems that conjunction search is based on both excitatory and inhibitory mechanisms. All stimulus features are activated in the initial analysis of the display, and therefore, some distractor features might interfere with target features. When the task is easy, distractor interference is small; therefore, attention is guided to the target and target information gains access to the response system. In this case, little or no distractor inhibition may be required. However, when the task is more difficult, distractor interference is greater; therefore, an inhibitory mechanism must suppress distractor information. In other words, when selection is easy, the inhibitory mechanism may not be necessary, whereas when selection is difficult, the inhibitory mechanism is required, resulting in suppression.

Cave and his colleagues (Cepeda et al., 1998; Kim \& Cave, 1995) as well as Horowitz and Wolfe (1996) found location-based suppression in conjunction search. Their data suggest that distractor locations are inhibited when participants search for a target. In the present study, the manipulation of the priming conditions was associated with stimulus features (color and form) rather than stimulus locations. Therefore, the facilitation and suppression found in the present study suggest that activation and inhibition are associated not only with stimulus locations (location based) but also with stimulus features (feature based).

In the present study, suppression was obtained for the CR condition but not for the FR condition in Experiment 1. One possible reason for the different results between two features (color and form) might be related to the finding by Egeth et al., (1984; see also Kaptein, Theeuwes, \& van der Heijden, 1995). They showed that participants can focus on one dimension in visual search and use it as a filter in target selection. Even though participants in the present study were not given any specific instruction to focus on either dimension, they might have put different weights on color and form in selecting the target.

The design of the present experiments was similar to negative priming in the sense that the carryover effects of the prime stimuli were measured in the probe trials. Therefore, the present study can be viewed as a variation of negative priming. In that case, it is possible that retrieval of episodic memory (e.g., Neill, 1997; Neill, Valdes, Terry, \& Gorfein, 1992) as well as temporal discrimination (Milliken et al., 1998) are involved in the priming effects observed in the present study. However, there are some differences between the present study and typical negative priming. For example, negative priming has been found in various tasks, including identification (e.g., Allport et al., 1985; Tipper, 1985), same-different matching (e.g., DeSchepper \& Treisman, 1996; Neill, Lissner, \& Beck, 1990), lexical decision (e.g., Yee, 1991), and localization (e.g., Tipper, Brehaut, \& Driver, 1990; Tipper et al., 1994). However, the present design was a target present/absent design and a probe target was presented before each prime and probe trial. Furthermore, because of the requirement of conjunction search, stimulus fea- 
tures of the prime display (color and form) were independently manipulated in the probe display.

The pattern of the present data is also different from that of typical negative priming. In the present study, the magnitude of suppression increased as set size increased; however, negative priming is usually observed with small set size. For example, Neumann and DeSchepper (1992) examined the effects of set size on the magnitude of negative priming. They manipulated the set size with three levels (one, two, or three distractors) and found that the magnitude of negative priming decreased as set size increased. Lavie and Tsal (1994) interpreted the results of Neumann and DeSchepper as consistent with their perceptual load hypothesis. The perceptual load hypothesis (see also Lavie, 1995; Lavie \& Cox, 1997) claims that the locus of attentional bottleneck (early vs. late selection) depends on perceptual load, which is determined by set size. When set size is small, perceptual load is low. In this case, distractor information is processed because attentional resources spill over to distractors, resulting in late selection. On the other hand, when set size is large, perceptual load is high. In this case, distractor information tends not to be processed, because there are not enough attentional resources left for processing of distractors, resulting in early selection. According to the perceptual load hypothesis, the magnitude of negative priming decreases as set size increases, because distractor information is processed to a greater extent when perceptual load is low. Therefore, Neumann and DeSchepper's results are consistent with the perceptual load hypothesis. The present data, however, seem inconsistent with the perceptual load hypothesis, because suppression was obtained only for larger set size. However, there is a fundamental difference between the design of Neumann and DeSchepper and the present one. In Neumann and DeSchepper's experiments, all distractors were different from one another in form and color; therefore, the number of different types of distractors increased as set size increased. On the other hand, there were always two types of distractors in the present study because the task was conjunction search. Thus, the number of distractor types remained constant regardless of set size. It is possible that in Neumann and DeSchepper's study, attentional resources were divided across all distinct distractor features. In such a case, each distractor might have been inhibited less as set size increased, resulting in weaker negative priming. However, in the present study, because the number of distractor types remained constant, it is possible that the effects of distractor inhibition were accumulated as set size increased, resulting in the greater magnitude of suppression.

In summary, the present study supported the feature activation and inhibition hypotheses. There seem to be two underlying mechanisms in conjunction search. One is based on activation of target-relevant features and functions regardless of set size, although the present results are not conclusive in this regard. The other mechanism is based on inhibition of target-irrelevant features and functions when set size is larger.

\section{REFERENCES}

Allport, D. A., Tipper, S. P., \& Chmiel, N. R. J. (1985). Perceptual integration and postcategorical filtering. In M. I. Posner \& O. S. M. Marin (Eds.), Attention and Performance XI (pp. 107-132). Hillsdale, NJ: Erlbaum.

Cepeda, N. J., Cave, K. R., Bichot, N. P., \& Kim, M.-S. (1998). Spatial selection via feature-driven inhibition of distractor locations. Perception \& Psychophysics, 60, 727-746.

DeSchepper, B., \& Treisman, A. (1996). Visual memory for novel shapes: Implicit coding without attention. Journal of Experimental Psychology: Learning, Memory, \& Cognition, 22, 27-47.

Duncan, J., \& Humphreys, G. W. (1989). Visual search and stimulus similarity. Psychological Review, 96, 433-458.

Duncan, J., \& Humphreys, G. W. (1992). Beyond the search surface: Visual search and attentional engagement. Journal of Experimental Psychology: Human Perception \& Performance, 18, 578-588.

Egeth, H. E., Virzi, R. A., \& Garbart, H. (1984). Searching for conjunctively defined targets. Journal of Experimental Psychology: Human Perception \& Performance, 10, 32-39.

Friedman-Hill, S., \& Wolfe, J. (1995). Second-order parallel processing: Visual search for the odd item in a subset. Journal of Experimental Psychology: Human Perception \& Performance, 21, 531-551.

Horowitz, T., \& Wolfe, J. M. (1996, November). Inhibitory and facilitatory guidance in visual search. Paper presented at the 37th Annual Meeting of the Psychonomic Society, Chicago.

Kaptein, N. A., Theeuwes, J., \& van der Heijden, A. H. C. (1995). Search for a conjunctively defined target can be selectively limited to a color-defined subset of elements. Journal of Experimental Psychology: Human Perception \& Performance, 21, 1053-1069.

KIM, M.-S., \& CAVE, K. R. (1995). Spatial attention in visual search for features and feature conjunctions. Psychological Science, 6, 376-380.

LAVIE, N. (1995). Perceptual load as a necessary condition for selective attention. Journal of Experimental Psychology: Human Perception \& Performance, 21, 451-469.

Lavie, N., \& Cox, S. (1997). On the efficiency of visual selective attention: Efficient visual search leads to inefficient distractor rejection. Psychological Science, 8, 395-398.

Lavie, N., \& TsaL, Y. (1994). Perceptual load as a major determinant of the locus of selection in visual attention. Perception \& Psychophysics, 56, 183-197.

Maljkovic, V., \& NaKayama, K. (1994). Priming of pop-out: I. Role of features. Memory \& Cognition, 22, 657-672.

Maljkovic, V., \& Nakayama, K. (1996). Priming of pop-out: II. The role of position. Perception \& Psychophysics, 58, 977-991.

McLeod, P., Driver, J., \& CRISP, J. (1988). Visual search for conjunctions of movement and form in parallel. Nature, 332, 154-155.

Milliken, B., Joordens, S., Merikle, P. M., \& Seifert, A. E. (1998). Selective attention: A reevaluation of the implications of negative priming. Psychological Review, 105, 203-229.

Nakayama, K., \& Silverman, G. H. (1986). Serial and parallel processing of visual feature conjunctions. Nature, 320, 264-265.

NeILL, W. T. (1977). Inhibitory and facilitatory processes in selective attention. Journal of Experimental Psychology: Human Perception \& Performance, 3, 444-450.

NeILl, W. T. (1997). Episodic retrieval in negative priming and repetition priming. Journal of Experimental Psychology: Learning, Memory, \& Cognition, 23, 1291-1305.

Neill, W. T., Lissner, L. S., \& Beck, J. L. (1990). Negative priming in same-different matching: Further evidence for a central locus of inhibition. Perception \& Psychophysics, 48, 398-400.

Neill, W. T., Valdes, L. A., Terry, K. M., \& Gorfein, D. S. (1992). The persistence of negative priming: II. Evidence for episodic retrieval. Journal of Experimental Psychology: Learning, Memory, \& Cognition, 18, 993-1000.

Neumann, E., \& DeSchepper, B. G. (1992). An inhibition-based fan 
effect: Evidence for an active suppression mechanism in selective attention. Canadian Journal of Psychology, 46, 1-40.

TIPPER, S. P. (1985). The negative priming effect: Inhibitory priming by ignored objects. Quarterly Journal of Experimental Psychology, 37A, 571-590.

Tipper, S. P., Brehaut, J. C., \& Driver, J. (1990). Selection of moving and static objects for the control of spatially directed action. Journal of Experimental Psychology: Human Perception \& Performance, 16, 492-504.

Tipper, S. P., Weaver, B., \& Houghton, G. (1994). Behavioral goals determine inhibitory mechanisms of selective attention. Quarterly Journal of Experimental Psychology, 47A, 809-840.

Treisman, A. (1988). Features and objects: The Fourteenth Bartlett Memorial Lecture. Quarterly Journal of Experimental Psychology, 40A, 201-237.

Treisman, A. (1993). The perception of features and objects. In A. D. Baddeley \& L. Weiskrantz (Eds.), Attention: Selection, awareness, and control. A tribute to Donald Broadbent (pp. 5-35). Oxford: Oxford University Press, Clarendon Press.
Treisman, A., \& Gelade, G. (1980). A feature-integration theory of attention. Cognitive Psychology, 12, 97-136.

Treisman, A., \& Gormican, S. (1988). Feature analysis in early vision: Evidence from search asymmetries. Psychological Review, 95, 15-48.

Treisman, A., \& Sato, S. (1990). Conjunction search revisited. Journal of Experimental Psychology: Human Perception \& Performance, 16, 459-478.

Wolfe, J. M. (1994). Guided Search 2.0: A revised model of visual search. Psychonomic Bulletin \& Review, 1, 202-238.

Wolfe, J. M., Cave, K. R. \& Franzel, S. L. (1989). Guided search: An alternative to the feature integ ration model for visual search. Journal of Experimental Psychology: Human Perception \& Performance, 15, 419-433.

YeE, P. L. (1991). Semantic inhibition of ignored words during a figure classification task. Quarterly Journal of Experimental Psychology, 43A, 127-153.

(Manuscript received September 23, 1998; revision accepted for publication January 27, 2000.) 